\title{
EFFECTS OF OPTIONS ON FINANCIAL STABILITY Chiara OLDANI ${ }^{1}$
}

\section{Abstract}

The lack of collateralized trading in the OTC derivatives market and the absence of any system for the resolution of cross exposures have been highlighted as major causes of the collapse of assets prices during the financial crisis. According to the perfect market hypothesis derivatives are a zero sum game (according to BlackScholes pricing models) and do not add new risk to the market or modify existing risk. However, these virtues only apply in the real world in the presence of effective regulation, control, and supervision. The perverse effects of the financial crisis suggest that it is time to rethink the standard finance theory approach to derivatives.

Derivatives and the Finance Theory

Finance theory relies heavily on the perfect market hypothesis which tells us that financial derivatives are powerful tools for investors, banks, and governments to hedge, smooth financial costs, and create opportunities. According to the perfect market hypothesis derivatives are a zero sum game (according to Black-Scholes pricing models) and do not add new risk to the market or modify existing risk. However, these virtues only apply in the real world in the presence of effective regulation, control, and supervision.

The regulation of derivatives in the present global financial system is not homogenous and the controls placed on investors vary across countries and investor clas-

\footnotetext{
${ }^{1}$ Chiara OLDANI, Lecturer of Economics, University of Viterbo "La Tuscia" and Director of Re-
} search, Assonebb. 
ses, leaving room for regulatory arbitrage. The most obvious example is the $\$ 67$ trillion of traditional securities and OTC derivatives traded in 2012 in the so-called shadow banking system, a system that operates with almost no supervision or monitoring. The lack of collateralized trading in the OTC derivatives market and the absence of any system for the resolution of cross exposures have been highlighted as major causes of the collapse of assets prices during the financial crisis. This real world experience suggests that it is time to rethink the standard finance theory approach to derivatives.

\section{The Subprime Crisis}

One of the initial shocks in the subprime crisis came when it was announced that it was impossible to value the off balance sheet assets and liabilities of a primary global bank. This generated the panic in August 2007 and the crisis spread like a deadly plague. Investors could not be sure of the true market value of their assets and liabilities. Initial credit ratings were quickly discarded as they were no longer relevant to the new market conditions of extreme liquidity shortage that was itself the result of the uncertainty on the value of assets pledged as collateral. This uncertainty depressed consumption and investment, and finally forced governments to inject resources to rescue banks and industries. The additional debt undertaken by governments to prop up the collapse of equity in the private financial system led to second crisis-the sovereign debt crisis.

The subprime crisis revealed the systemic and perverse effects of improper risk management practices, weak regulation and supervision, and ineffective control due to the failure of regulators to comprehend the massive size of the shadow markets. The virtues attributed to derivatives by standard finance theory evaporated entirely during the crisis and these same virtues became vices that contributed substantial to systemic risk. The roots of the subprime crisis thus may be seen to lie in dangerous 
market imperfections and regulatory weaknesses. The appropriation of the profits of the finance industry by management and employees at the expense of shareholders and the economy as a whole has not been eliminated following the subprime crisis. Banks and investment firms still pay exorbitant bonuses to traders and brokers, while taxpayers and workers (employed and unemployed) pay the cost of the crisis (socialization of losses).

The Financial Instability Hypothesis and Options

The Financial Instability Hypothesis (FIH) (Minsky, 1977) provides a powerful alternative to standard Neo-Classical and New Keynesian models, which cannot provide a satisfactory integration of the real and the financial sides of macro-models. The $\mathrm{FIH}$ also describes how financial markets become unstable even in the absence of an exogenous shock. The expansionary money policies of the new millennium, financial globalization, and the enormous profits created in the derivatives market all fuelled the share of finance in GDP. This process is endogenous to the capitalist economy, and the FIH captures these features.

Financial innovation plays a key role in the growth of the capitalist economy. Financial innovation contributes to the endogenous creation of profits from new forms of investment during periods of tranquility and stability. However, according to the $\mathrm{FIH}$, regulation and supervision should be used during turbulent periods to maintain a stable environment for investors and firms (see Oldani, 2008). Financial derivatives are the most developed financial innovation seen in recent decades; among these innovations, options represent an important share of the market. According to finance and economic theory, options expand portfolio allocation opportunities, increase market liquidity, and improve the pricing mechanism. When options are used for hedging, they contribute to better portfolio management for firms and investors. Options are introduced in the FIH by means of the hedging opportunities they pro- 
vide to firms, and thus influence the saving function and, as a result, the equilibrium. In the absence of shocks and with proper regulation and supervision, options contribute to better portfolio management, as finance theory states. However, in the runup to the crisis, the benefits of this innovation led to a decline in the recognition of the important role of regulation in assuring these benefits. The failure of regulation led to the disappearance of the benefits of these instruments as a means to finance investment and promote growth. Instead innovative instruments were increasingly used for speculative financing of higher and high leverage positions. This was an endogenous process by which the belief in the benefits that could be derived from these instruments led to the elimination of the formal regulations and supervision that were necessary to achieve these benefits.

When turbulence arose in these markets volatility increased, and the hedging strategies of investors became ineffective, aggravating financial payments by firms. The leverage effect of options multiplies losses, which has a negative impact on the debt accumulation process and the investment decisions of firms. The reaction of firms can further intensify the downturn by selling assets, increasing the debt or trying to raise new capital. In the presence of the massive use of options, financial fragility becomes more pronounced. Regulation is the tool needed to safeguard financial stability, as Minsky predicted at a time when financial markets were less sophisticated. During the crisis derivatives were like gasoline poured on a fire, but they were not the reason for the crash. Regulation of the global financial system was inappropriate; it allowed unregulated investors (like shadow banks) to expand their balance sheets without sufficient capitalization.

The contribution of options to financial instability is similar to other financial securities previously investigated in the $\mathrm{FIH}$ literature in the presence of weak regulation and control, such as bonds and shares. They substantially worsen financial crises. An empirical investigation to measure the impact of derivatives on stability is not 
possible, since data are not provided on a high frequency basis, and are not provided by the shadow banks that represent a large share of the market.

The lack of data on the shadow banking system (trading, exposure, market concentration counterpart and so on) and on OTC derivatives trading represents a clear obstacle to a safe exit from the meltdown. Confidence in these markets cannot be restored until specific responsibilities are defined and a strong regulatory response is put in place.

Bibliography

H.P. Minsky. "The Financial Instability Hypothesis: an Interpretation of Keynes and Alternative to Standard Theory". Challenge, March-April, 1977: 20-27.

C. Oldani. Governing Global Derivatives: Challenges and Risks. Ashgate Publishers, London, 2008. (http://www.ashgate.com/isbn/9780754674641) 